\title{
APLICAÇÃO DE TÉCNICA DE GEOPROCESSAMENTO EM ÁREAS DEGRADADAS DE MATA CILIAR E SUA CORRELAÇÃO COM QUALIDADE DA ÁGUA NUMA SUB- BACIA HIDROGRÁFICA
}

\author{
Ivalde Belluta ${ }^{1}$; Renato de Casio Ferreira Neves ${ }^{1}$; Fábio Eduardo de Souza Zampieri ${ }^{2}$; \\ Ramon Felipe Bicudo da Silva ${ }^{2}$; Anderson Antonio da Conceição Sartori ${ }^{2}$; Célia Regina \\ Lopes Zimback ${ }^{2}$ \\ ${ }^{1}$ Depto de Química e Bioquímica - IB/UNESP, Botucatu - SP \\ ${ }^{2}$ Universidade Estadual Paulista - UNESP/FCA \\ Grupo de Estudos e Pesquisas Agrárias Georreferenciadas - GEPAG \\ Caixa Postal 237 - 18610-307 - Botucatu - SP, Brasil \\ ibelluta@fca.unesp.br, renatocassio_neves@hotmail.com, \\ fabiexzampieri@hotmail.com.ramonbicudo@yahoo.com.br, sartori80@gmail.com, rzimback@fca.unesp.br
}

\section{RESUMO}

O estudo do meio físico de uma bacia hidrográfica é condição básica para o planejamento bem sucedido da preservação da mata ciliar e conservação e produção de água. Os objetivos do presente trabalho foram analisar e quantificar a evolução espacial e temporal (1984 e 2010) através de imagens de satélite Landsat-5, da sub-bacia do córrego do Cintra, Botucatu SP, processadas pelo sistema computacional IDRISI Andes, e analisar a qualidade da água pelos parâmetros pH, CE, OD e a $\mathrm{DBO}_{5}$ em 4 pontos distintos nos anos de 1999, 2008 e 2009. Considerando a área de 1076,48ha da sub-bacia, observou-se que a classe pastagem em 1984 foi reduzida em 25,55\% em 2010 resultando no aumento das demais classes. A mais importante foi a classe mata nativa e reflorestamento, pois aumentou 5,08\%, o que demonstra recuperação da mata ciliar. Foram identificadas áreas degradadas situadas no limite inferior da sub-bacia $\left(\mathrm{P}_{3} \mathrm{e}\right.$ $\left.\mathrm{P}_{4}\right)$ e contaminação pontual $\left(\mathrm{P}_{1}\right.$ e $\left.\mathrm{P}_{2}\right)$ com piora na qualidade da água nos demais pontos nos períodos de 2008 e 2009. Restauração e manejo de sucessão ecológica nas áreas degradadas e o monitoramento da qualidade da água nos pontos 1 e 2 serão necessários para restabelecer a condição natural na área de estudo.

Palavra chave: Georreferenciamento, córrego do Cintra, mata ciliar, hidrisi Andes, parâmetros físico-químicos

BELLUTA, I.; NEVES, R. de C. F.; ZAMPIERI, F.E. de S.; SILVA, R.F.B. da; SARTORI, A.A. da C.; ZIMBACK, C.R.L.

GEOPROCESSING TECHNIQUE USED IN DEGRADED AREAS OF RIPARIAN FOREST AND THEIR CORRELATION TO THE WATER QUALITY IN A WATERSHED

\section{ABSTRACT}


Studying the physical environment of a watershed is the basic condition for a successful planning of the riparian forest preservation, and for water production and conservation. The aims of the present study were to analyze and quantify the spatial and temporal evolution (1984 and 2010) using Landsat-5 satellite images of Cintra Stream sub-watershed, Botucatu, São Paulo State, Brazil, processed by the software IDRISI Andes, as well as to analyze the water quality through the parameters pH, EC, DO and BOD5 at 4 different sites in the years 1999, 2008 and 2009. Considering the 1076.48ha area of the sub-watershed, the pasture class of 1984 was reduced by $25.55 \%$ in 2010 , resulting in an increase in the remaining classes. The most important class was native forest and reforestation since it had an increase of $5.08 \%$, which indicates recovery of the riparian forest. Degraded areas were identified close to the inferior limit of the sub-watershed (P3 and P4), as well as local contamination (P1 and P2) with worsening of the water quality in the remaining sites in the periods 2008 and 2009. Recovery and management of the ecological succession of degraded areas and water quality monitoring at 1 and 2 sites will be necessary to reestablish the natural condition of the area studied.

Key words: Georeferencing, Cintra Stream, riparian forest, IDRISI Andes, physicochemical parameters

\section{INTRODUÇÃO}

Em um planejamento regional integrado de recursos hídricos deve-se adotar como unidade territorial de planejamento a bacia hidrográfica na qual o curso d'água se insere.

A bacia hidrográfica é uma área de captação natural da água da chuva que proporciona o escoamento para o canal principal e seus tributários, sendo seu limite superior, o divisor de águas e a delimitação inferior a saída da bacia (Lima, 1996) apud Santos (2004). É a unidade de estudo que mais favorece o desenvolvimento de pesquisas relacionadas ao ciclo hidrológico e que se ajusta aos objetivos de planejamento agrícola e ambiental (Lima, 2003). Um dos principais impactos produzidos no ciclo hidrológico é a rápida taxa de urbanização e os efeitos negativos na saúde humana, além de impactos como enchentes, deslizamentos e desastres provocados pelo desequilíbrio no escoamento das águas (Tundisi, 2005). Segundo Candessus et al (2010), sem água as células não poderiam trocar informações. Sem a água os grandes ciclos reguladores do ecossistema não poderiam funcionar. A água é essencial à origem da vida, constitui o meio da maioria dos seres vivos e é o principal constituinte celular (Candessus et al, 2010).

Assim, os rios são fontes finitas de água e sistema de drenagem de uma bacia hidrográfica. Toledo \& Nicolella (2002) os definem como sistemas complexos caracterizados como escoadouros naturais das áreas de drenagens adjacentes e a complexidade destes sistemas lóticos deve-se ao uso da terra, geologia, tamanho e formas das bacias de drenagem, além das condições climáticas locais.

As áreas vegetadas no entorno dos rios são chamadas matas ciliares, matas de galerias ou ripárias e são fundamentais para proteção dos recursos hídricos, integridade ecológica nas áreas de várzea, além de funcionarem como corredor ecológico para a fauna e flora (Paula Lima \& Zákia, 2000). Outra importante função é criar corredores para favorecer o fluxo gênico entre remanescentes florestais e fornecer alimentação e abrigo para a fauna e funcionar como barreiras naturais contra a disseminação de pragas e doenças nas lavouras (Chabaribery et al. 2008). 
A intervenção humana sob a mata ciliar, além de ser proibida pela legislação federal (Brasil, 1965), causa uma série de danos ambientais. Segundo Camdessus et al. (2010), com a conquista de terras agrícolas ou à exploração intensiva das matas, o desmatamento está, em certas áreas, na origem da erosão e da sedimentação dos rios. Apesar das interferências humanas, o principal atributo dos ecossistemas é a sua capacidade de mudança temporal (Engel \& Parrota, 2003), isso porque eles são alterados no tempo e no espaço em razão de respostas da vegetação a regimes de distúrbios (Martins et al, 2002).

Estudos de Mossoud et al. (2006), reforçaram a noção da necessidade da gestão de fontes de contaminação pontual e difusa, pois deveriam ser integradas às origens da contaminação associadas ao uso do solo e efeitos deletérios na qualidade de água. Neste contexto, a falta de boa qualidade de água dificulta o desenvolvimento econômico local e reduz o potencial de sustentabilidade em longo prazo.

No interior do Estado de São Paulo, a Coordenadoria de Assistência Técnica Integral CATI (2010) implantou o Programa de Microbacias Hidrográficas, em uma parceria entre o Governo do Estado e o Banco Internacional para a Reconstrução e o Desenvolvimento (BIRD), além de prefeituras municipais. O programa é executado pela Secretaria de Agricultura e Abastecimento, por meio da CATI, com o objetivo de estabelecer uma política de preservação do solo e da água. A atuação é feita em todo o Estado, incentivando as comunidades rurais a reverem ações, valores culturais e sociais, além de apoiar atividades que propiciam resultados positivos na recuperação ambiental e na qualidade de vida dessas comunidades de maneira sustentável.

Assim, este trabalho permitiu conhecer a dinâmica das alterações constatadas no tempo e no espaço, pois depende da comparação de levantamentos e quantificações efetuados em diferentes períodos. A comparação entre mapas elaborados a partir de uma série temporal de imagens permite inferências retrospectivas sobre os processos de ocupação terrestre, subsidio para uma análise do histórico ocupacional de uma determinada região. $\mathrm{Na}$ análise entre produtos obtidos em diferentes datas deve-se atentar à qualidade da água do córrego e às mudanças da paisagem local, causadas em decorrência das alterações do uso e ocupação do solo. A sub-bacia do Córrego do Cintra em estudo passou por extensa ocupação humana, onde fontes pontuais e difusas de contaminação e pequenas culturas de subsistência nas margens do córrego ocorreram persistentemente nos últimos anos (Belluta et al., 2010)

O estudo espaço-temporal da sub-bacia justifica-se pela necessidade de se criar um acervo de dados que sirvam de instrumento para a gestão do meio ambiente, principalmente, em ações que tentam dirimir os efeitos negativos na qualidade de água do córrego e no desmatamento da mata ciliar. Assim, os objetivos foram analisar e quantificar a evolução espacial e temporal (1984 e 2010) através de imagens de satélite e avaliar a qualidade de água do Córrego do Cintra em três períodos (1999, 2008 e 2009), no intuito de subsidiar a gestão de recursos hídricos e recomposição das áreas desprovidas de mata ciliar.

\section{MATERIAL E MÉTODOS}

O município de Botucatu está localizado na região centro-sul do Estado de São Paulo, entre as coordenadas geográficas $22^{\circ} 52^{\prime} 20^{\prime \prime} \mathrm{S}$ e $48^{\circ} 26^{\prime} 37^{\prime \prime} \mathrm{W}$ Gr., a $230 \mathrm{~km}$ da capital. Esta região apresenta uma geomorfologia que propicia a formação de quedas d'água, cujo relevo 
chamado de "Cuesta", é divisor de águas entre as Bacias Hidrográficas do Rio Paranapanema e a do Rio Tietê, situado a $950 \mathrm{~m}$ de altitude (Souza et al., 2003).

A sub-bacia do Córrego do Cintra, situada a noroeste da cidade de Botucatu, nasce dentro do Campus da UNESP, em Rubião Junior seguindo seu fluxo ao norte até a represa da Barra Bonita (Rio Tietê) (Figura 1). Da nascente à foz do Cintra, o curso principal mede aproximadamente $5,5 \mathrm{~km}$ e sofre influências de áreas de pastos, pomares, dessedentação de animais em áreas desprovidas de mata ciliar, cultivo de grãos e hortaliças.

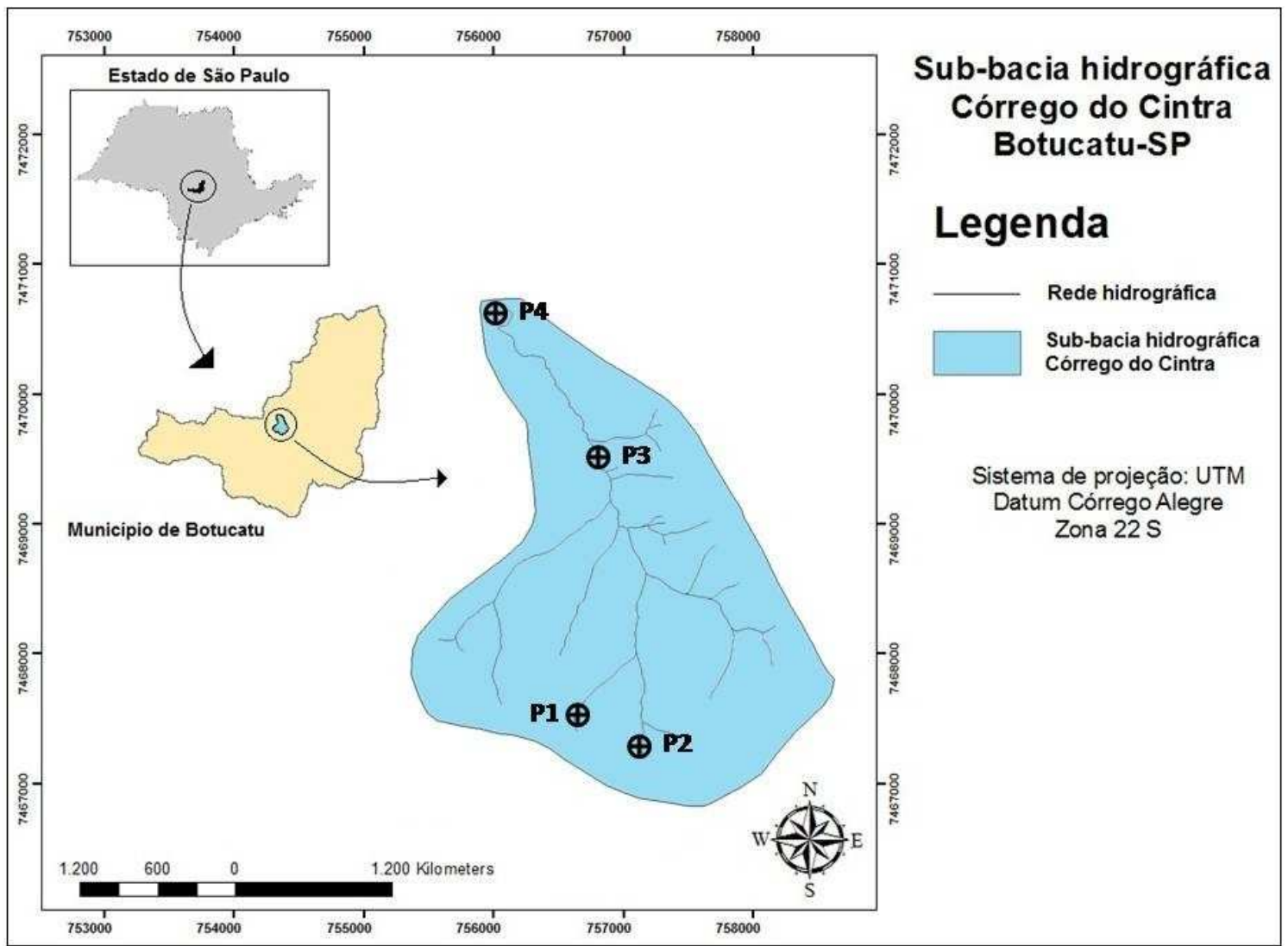

Figura 1. Limite, rede de drenagem e localização dos pontos de coleta na sub-bacia hidrográfica do córrego do Cintra - Botucatu SP.

A metodologia para o processamento das imagens na referida área de estudo, foi aplicada segundo Eastman (2006), através de estudos de imagens no formato digital do satélite Landsat-5 que foram processadas através do sistema computacional IDRISI Andes. As funções utilizadas no processamento das imagens foram Display (STRETCH e COMPOSITE) e Reformat (RESAMPLE e WINDOW); no processo de classificação foram GIS Analysis (Signature Development, Hard Classifiers).

$\mathrm{Na}$ fase de pré-processamento, as imagens foram preparadas para a realização da classificação. Primeiramente foi aplicado o realce com o intuito de melhorar a qualidade visual das imagens, isto é, para ampliar o contraste das feições da cena. Para correção dos erros contidos na imagem devido à movimentação do satélite e curvatura da Terra (projeção e sistema de 
referência) foi executada a retificação geométrica. Neste processo fez-se o registro, através das coordenadas geográficas, dos pontos de controle utilizando uma imagem previamente registrada, onde pontos devidamente identificados (georreferenciados) foram associados aos pixels da imagem de interesse. Finalmente, a cena imageada foi reduzida de modo a restringir-se apenas à área de estudo.

As bandas selecionadas para classificação foram TM3, TM4 e TM5, pois correspondem às regiões do espectro eletromagnético que melhor representam alvos agrícolas importantes para o planejamento.

Depois de identificadas as classes espectrais referentes à classe de uso do solo, foram agrupadas, desconsiderando-se as demais classes.

A classificação escolhida foi a supervisionada e as cinco classes de uso do solo foram localizadas na imagem. Em seguida, foram digitalizados polígonos em torno dessas áreas, atribuindo um identificador para cada tipo de cobertura. Após definidas as áreas de treinamento, os pixels nelas contidos foram analisados e assinaturas espectrais foram criadas para cada objeto. Finalmente, executou-se o classificador, onde todos os pixels foram classificados com igual probabilidade para cada classe de uso. Com a classificação obteve-se dados referente à área de uso e ocupação do solo bem como a área total da sub-bacia (1.076,48 ha).

Quanto as análises de qualidade de água foram utilizados dados obtidos no ano de 1999/2000 (Gralhóz \& Nogueira, 2006) e análises obtidas em 2 períodos, 2008 e 2009. Estas análises foram realizadas no Departamento de Química e Bioquímica do Instituto de Biociências da Universidade Estadual Paulista, UNESP Campus de Botucatu. Foi analisada a água em 4 pontos diferentes ao longo do curso d'água, desde a principal nascente $\left(\mathrm{P}_{1}\right)$ até a sua foz $\left(\mathrm{P}_{4}\right)$ dentro desta sub-bacia (Figura 1).

Quanto à periodicidade da coleta e amostragem, estas foram realizadas em Janeiro/2008 a Dezembro/2009 seguindo um cronograma de coleta trimestral. Para as determinações dos parâmetros Físico-Químicos, foram utilizados métodos recomendados pelo Standard Methods for the Examination of Water and Wastewater (Greenberg et al., 2005). O Potencial Hidrogeniônico $(\mathrm{pH})$, foi determinado utilizando um pHmetro Hanna Instruments, modelo HI 221. A Condutividade Elétrica (CE) foi determinada utilizando um condutivímetro Hanna Instruments, modelo HI 2300.

A Demanda Bioquímica de Oxigênio $\left(\mathrm{DBO}_{5}\right)$ foi determinada utilizando o método de incubação por 5 dias e o Oxigênio Dissolvido (OD) pelo método de Winkler modificado pela azida sódica.

$\mathrm{O} \mathrm{P}_{1}$ foi escolhido devido ao lançamento de esgoto não tratado e o $\mathrm{P}_{2}$ devido a presença de efluente tratado da ETE-SABESP onde recebe todo o esgoto do Distrito de Rubião Júnior e do Campus da Unesp; o $\mathrm{P}_{3}$ devido proximidade do Bairro Vista Alegre considerando possíveis lançamentos de esgoto no córrego e $\mathrm{o}_{4}$ (Foz) devido a presença de áreas agropastoris localizados a montante.

Com o objetivo de verificar o comportamento de cada variável nos locais, foram realizadas análises de variância seguidas do teste de Tukey (Tukey's Studentized Range - HSD), ao nível de 5\% de significância (Sokal \& Rohlf, 1995). 


\section{RESULTADOS E DISCUSSÃO}

A classificação supervisionada das imagens de 1984 e 2010 possibilitou a definição de cinco classes de uso da terra (Pastagem, Mata Nativa e Reflorestamento, Solo Exposto e Ocupação Humana, Culturas, Corpos d'Água) nos 1.076,48 ha da área total de estudo que compreende a sub-bacia do Córrego do Cintra (Figuras 2).

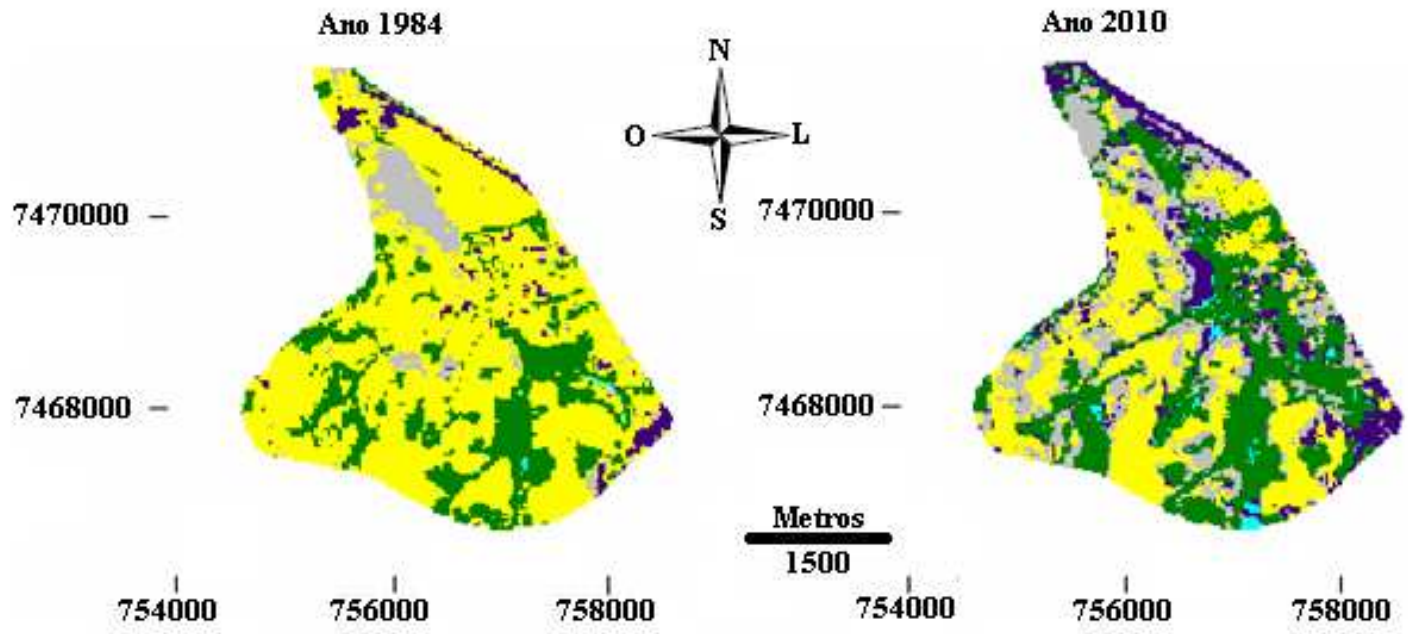

\section{Pastagem}

Mata nativa e reflorestamento

Solo exposto e ocupação humana Cultura

\section{Corpo d'água}

Figura 2. Uso e ocupação do solo na sub-bacia hidrográfica do córrego do Cintra - Botucatu (SP) em 1984 e 2010

Mesmo antes da classificação perceberam-se mudanças no uso e cobertura da terra em 1984 e 2010. Por outro lado, algumas classes apresentaram respostas espectrais muito semelhantes (culturas e mata nativa), o que dificultou também o processo de classificação monitorada, dificuldades essas também verificadas nos estudos de Eastman (2006).

O mapa de uso do solo mostra o elevado grau de fragmentação da região, demonstra a forte pressão antrópica exercida basicamente pelas pastagens, depois culturas, solo exposto e área urbana, sobre a mata nativa (Figuras 2). Em observação in loco nos limites da mata ciliar existente, o efeito de borda decorrentes dessa fragmentação, do fogo e do corte seletivo são bem visíveis como foi descrito por Durigan (2009). Estes fragmentos estão entremeados pela floresta aluvial (em diversos estágios de sucessão), culturas agrícolas entre vegetação de capoeira e áreas de transição de cerrado e cerradão na região. Estas diferentes fisionomias de vegetação remanescente de florestas passaram por avançado processo de devastação desde o período colonial cuja classificação fitogeográfica na região, segundo o IBGE (1992), é dita como Floresta Estacional Semidecídua considerada como uma das principais formações florestais do Estado de São Paulo.

As imagens obtidas da área estudada (Figuras 2) revelam o que ocorre na maior parte do interior do Estado de São Paulo, que se encontra com um déficit de cobertura vegetal muito 
grande. No entanto, neste período houve aumento na área regenerada de 20,86\% em 1984 para 25,94\% em 2010. Apesar do predomínio de área de pastagem, ao contrário da mata nativa, vem diminuindo gradativamente de 62,87\% em 1984 para 37,32\% em 2010 (Figura 3).

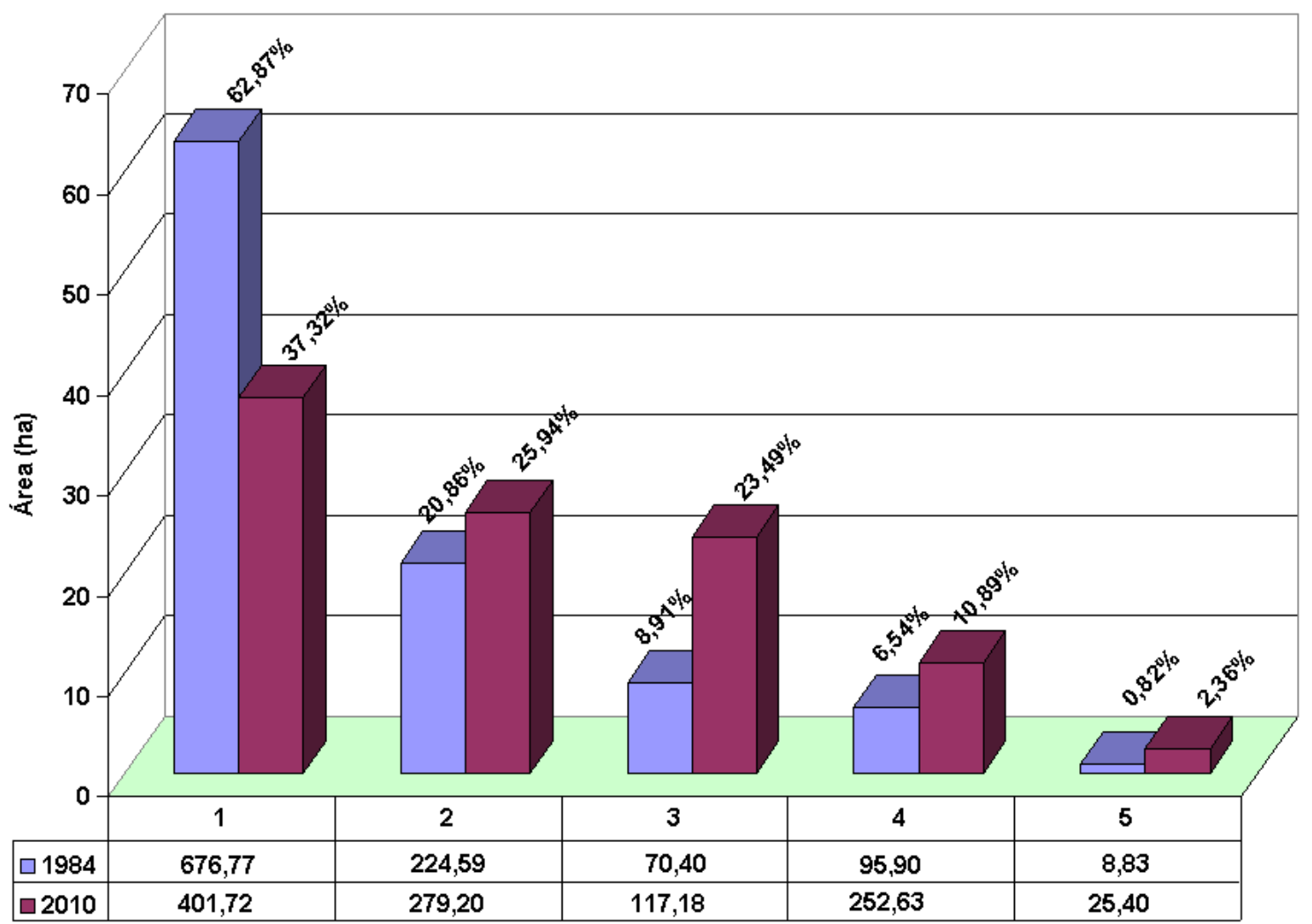

Figura 3. Distribuição da ocupação do Solo na região estudada nos 2 períodos. Classes: Pastagem (1); Mata nativa e reflorestamento (2); Culturas (3); Área urbana e solo exposto (4) e corpos d'água (5).

É problemática a localização das pastagens, pois muitas dessas estão junto às margens do Córrego do Cintra, onde deveria haver matas ciliares. Nos estudos de Alencar et al. (1996), nas áreas agrícolas da Amazônia Oriental, a cobertura da mata tende a aumentar e a pastagem e as culturas tendem a ocupar as mesmas áreas que vinham ocupando nos últimos 10 anos. Esta tendência pode ser explicada pela alta concentração de terras não produtivas e a falta de motivação para investimentos rurais.

Com a construção da composição de imagens através do programa Idrisi, evidenciou-se que a área onde deveria existir mata ciliar, protegida pelo Código Florestal (Brasil, 1965), já não existia mais antes de 1984, por que, quase toda a vegetação foi cortada para dar origem à agricultura local e pastagens. Então, aplicando-se a Legislação Florestal é possível verificar que boa parte das pastagens e agriculturas estão dentro destes limites. A única área de domínio antrópico, está localizado próximo ao divisor de águas no sentido Sul da sub-bacia, o Campus da Unesp de Botucatu, observado na imagem de 1984 (Figura 2). É observada a Faculdade de Medicina e pequenos fragmentos de matas em regeneração e reflorestamento e, a jusante, áreas 
de nascentes $\left(\mathrm{P}_{1}\right.$ e $\left.\mathrm{P}_{2}\right)$ com reduzida área de mata nativa. Desta maneira, segundo o Código Florestal, estas áreas deveriam cobrir $30 \mathrm{~m}$ de cada lado do rio e $50 \mathrm{~m}$ de raio nas nascentes, incluindo os vários rios tributários que desaguam no Cintra (Figura 1). O mesmo acontece na entorno dos pontos 3 e 4 (Figura 2), pois observa-se o predomínio de pastagem, culturas, solo exposto e o leito indefinido do córrego que dá lugar a área de várzea desprovida de mata ciliar. Já na imagem de 2010, observa-se um panorama diferente, cujas áreas de matas ciliares estão se regenerando a jusante da Faculdade de Medicina junto ao sistema ETE-SABESP $\left(\mathrm{P}_{2}\right)$. No $\mathrm{P}_{1}$, dentro do Campus da Unesp, toda área do seu entorno foi reflorestada com espécies nativas e exótica (eucalipto).

A montante e à direita do $\mathrm{P}_{3}$, está localizado o Bairro Vista Alegre em pleno desenvolvimento, arborizado e, à esquerda, o complexo de lagoas de piscicultura chamado Aracatu. As matas ciliares neste ponto do rio ainda não atingem os limites mínimos estabelecidos pela legislação, e a jusante, no $\mathrm{P}_{3}$ e $\mathrm{P}_{4}$, consideradas áreas alagadas, ainda continuam ausentes, porém em processo de regeneração. Segundo Schaefer et al (2009), quanto maior for o encharcamento do solo, mais impróprio torna-se o ambiente, ocorrendo, dessa forma, uma substituição de indivíduos arbóreos por elementos herbáceos, que propagam de pontos mais altos (melhor drenagem) para áreas mais baixas (pior drenagem). A lentidão da regeneração nestas áreas e o predomínio de gramíneas nos pontos 3 e 4 desde 1984 (Figura 2) é observado e a solução seria um plano de manejo de recuperação da mata original. Segundo Martins et al. (2009), entre os processos de sucessão florestal em áreas degradadas, destaca-se a transposição da serrapilheira, do banco de sementes e de galhadas, o manejo de regeneração natural, o resgate de plântulas e a semeadura direta com alta diversidade.

A mata nativa exuberante encontrada nesta sub-bacia está entre os pontos 2 e 3 (Figura 3). Observaram-se árvores com dossel irregular de 15 a $20 \mathrm{~m}$ de altura e presença de árvores emergentes de $25 \mathrm{~m}$ altura, com submata arbóreo-arbustiva densa.

As áreas urbanas e solo exposto encontradas dentro dos limites da sub-bacia, segundo os dados obtidos pelo Idrisi, foi de 6,54\% em 1984 para 10,89\% em 2010 e as áreas de culturas foram de 8,91\% (1984) para 23,49\% (2010) (Figuras 4), uma vez que a região apresenta atualmente cultura tipicamente familiar e de subsistência com culturas perenes e anuais.

Quanto à rede de drenagem da sub-bacia (Figura 1), não foi observada alteração nos 2 períodos, o que provavelmente poderia ter ocorrido pelas diferenças nos regimes de chuvas. Observou-se nas imagens, variação de 0,82\% em 1984 e 2,36\% em 2010 de corpos d'água caracterizados pelas lagoas de estabilização de esgoto- ETE-SABESP $\left(\mathrm{P}_{2}\right)$, com área aproximada de 2,5hectares (Souza, 2005) e lagoas utilizadas para pisciculturas e fins de recreação localizados ao longo da microbacia (Figura 2).

As análises de água realizadas no córrego do Cintra apontam, através do teste de Tukey, alterações significativas, e o Box plot nos dá um sumário completo dos dados, nos pontos e nos períodos, onde podemos ver a mediana, a dispersão, a simetria e potenciais outliers (Sokal \& Rohlf, 1995). Quanto aos parâmetros avaliados no presente estudo, estarão de acordo com o artigo $42^{\circ}$ da resolução 357/2005 do CONAMA, pois quando uma microbacia ainda não está enquadrada em nenhuma classe, esta deve seguir os índices da Classe II (Brasil, 2005).

A Tabela 1 revela que, com exceção do $\mathrm{P}_{1}, \mathrm{o} \mathrm{pH}$ entre os demais pontos e épocas não diferiram estatisticamente entre si. A amplitude dos valores obtidos do $\mathrm{pH}$ no $\mathrm{P}_{1}$ e demais pontos podem ser observados na Figura 4. $\mathrm{O}$ pH neste ponto e no primeiro período era neutro, 
demonstrando boas condições da água. Já nos períodos 2 e 3, há um decréscimo do pH tornandoo levemente ácido (Tabela 1).

Tabela 1. Resultados do teste de Tukey para o pH nos quatro pontos de coleta no córrego do Cintra, nos períodos de 1999, 2008 e 2009.

\begin{tabular}{ccccc}
\hline & \multicolumn{3}{c}{ Épocas } & \\
\cline { 2 - 4 } Pontos & Período 1 & Período 2 & Período 3 & Média geral dos pontos \\
\hline $\mathrm{P}_{1}$ & $7,0 \mathrm{a}$ & $6,3 \mathrm{~b}$ & $6,2 \mathrm{~b}$ & 6,5 \\
& $\mathrm{~A}$ & $\mathrm{~B}$ & $\mathrm{~B}$ & 0,4 \\
$\mathrm{P}_{2}$ & 0,3 & 0,2 & 0,2 & 6,9 \\
& $7,0 \mathrm{a}$ & $6,6 \mathrm{a}$ & $7,1 \mathrm{a}$ & \\
& $\mathrm{A}$ & $\mathrm{AB}$ & $\mathrm{A}$ & 0,4 \\
$\mathrm{P}_{3}$ & 0,3 & 0,2 & 0,6 & 7,0 \\
& $7,0 \mathrm{a}$ & $7,2 \mathrm{a}$ & $6,8 \mathrm{a}$ & 0,3 \\
& $\mathrm{~A}$ & $\mathrm{~A}$ & $\mathrm{~A}$ & 7,0 \\
$\mathrm{P}_{4}$ & 0,3 & 0,2 & 0,2 & 0,3 \\
& $7,0 \mathrm{a}$ & $7,2 \mathrm{a}$ & $6,9 \mathrm{a}$ & \\
& $\mathrm{A}$ & $\mathrm{A}$ & $\mathrm{A}$ & 6,8 \\
Média geral das & 0,5 & 0,2 & 0,3 & 0,4 \\
épocas & 7,0 & 6,8 & 6,7 &
\end{tabular}

$\mathrm{P}<0,001$ para efeito da interação época* ponto

Letras minúsculas comparam médias de época dentro de cada ponto

Letras maiúsculas comparam médias de ponto dentro de cada época

A amplitude e dispersão do $\mathrm{pH}$ (Figura 4), demonstram que, em várias coletas, nos 3 períodos, o $\mathrm{pH}$ variou significativamente no $\mathrm{P}_{1}$, e nos demais pontos, o $\mathrm{pH}$ tendeu a neutralidade. Segundo Nuvolari et al. (2003), o estudo do pH mostra que o caráter ácido ocorre devido a maior concentração de matéria orgânica em decomposição (geração de $\mathrm{CO}_{2}$ e formação de ácido carbônico). Além disso, no momento e local da coleta foram observadas características organolépticas (turbidez, odor) da água, típica de esgoto.

Segundo WEF (1995), os compostos odoríferos incluem as moléculas orgânicas e inorgânicas (ácido sulfídrico e amônia), geralmente resultantes da atividade biológica, as quais decompõem a matéria orgânica e formam uma variedade de gases mal odorantes tais como: indols, escatoles, mercaptanas e aminas. Sabe-se que o $\mathrm{P}_{1}$ está localizado no Jardim Botânico onde todo o esgoto gerado no Campus da Unesp de Botucatu era lançado a montante deste ponto. Após o ano 1997, com a construção das lagoas de estabilização (ETE_SABESP), todo esgoto foi encaminhado ao tratamento (Gralhóz \& Nogueira, 2006). 


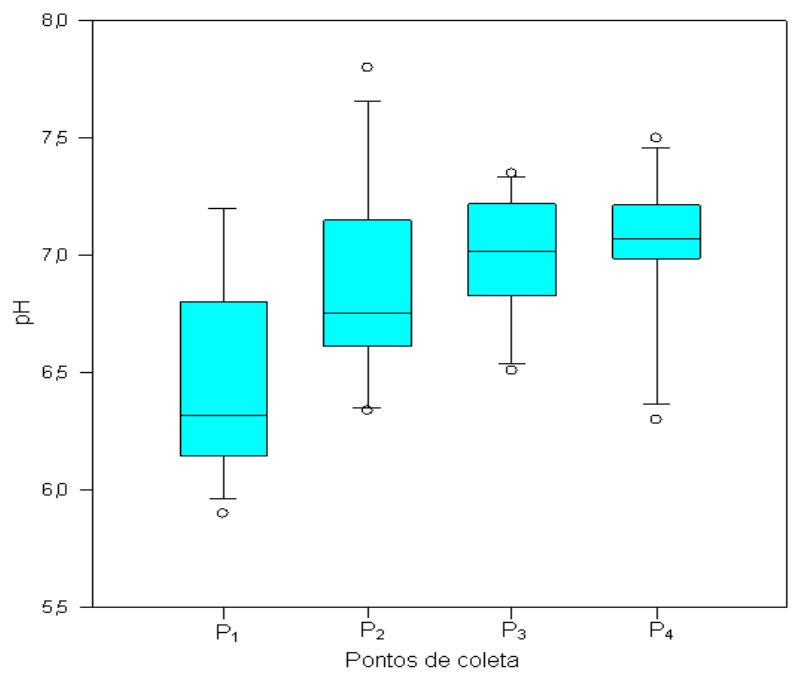

Figura 4. Box plot e comparação entre médias (Teste de Tukey) mostrando a variação do pH com diferenças significantes no córrego do Cinta nos quatro pontos de coleta em 1999, 2008 e 2009.

$\mathrm{O} \mathrm{P}_{2}$, situado a jusante das lagoas de estabilização, recebe a carga de esgoto tratado do sistema ETE_SABESP onde é monitorado periodicamente pela Sabesp. Tanto o $\mathrm{P}_{1}$ como o $\mathrm{P}_{2}$, influencia na qualidade da água ao longo do seu percurso devido a carga de matéria orgânica. Segundo Silva et al (1998), um gradiente de poluição lançado na cabeceira do rio, permite mostrar o processo de autodepuração no percurso do rio, no entanto ocorre alteração na qualidade da água em relação à sua nascente. Este processo também foi observado por Gralhóz e Nogueira (2006), Belluta et al (2009) e Belluta et al (2010ab) na presente área de estudo. Apesar dos resultados obtidos do $\mathrm{pH}$, em termos de qualidade de água, os valores são considerados normais entre 6 e 9, segundo a Resolução do Brasil (2005).

O comportamento do $\mathrm{pH}$ (Figura 5) nos 3 períodos separadamente e em todos os pontos, permitiu observar a amplitude dos seus valores. No Período 1, a mediana se mantém próximo da neutralidade e a maioria dos valores obtidos em todos os pontos, manteve-se próximo desta faixa. Nos Períodos 2 e 3, a amplitude dos valores de $\mathrm{pH}$ elevou-se consideravelmente, possivelmente devido ao aumento da carga do efluente no $\mathrm{P}_{1}$ e $\mathrm{P}_{2}$, pois de 1999 a 2009, houve a expansão do Campus da Unesp e o aumento da população de Rubião Júnior (IBGE, 2008) e, conseqüentemente, elevação da carga de esgoto a ser tratado no sistema ETE_SABESP. 


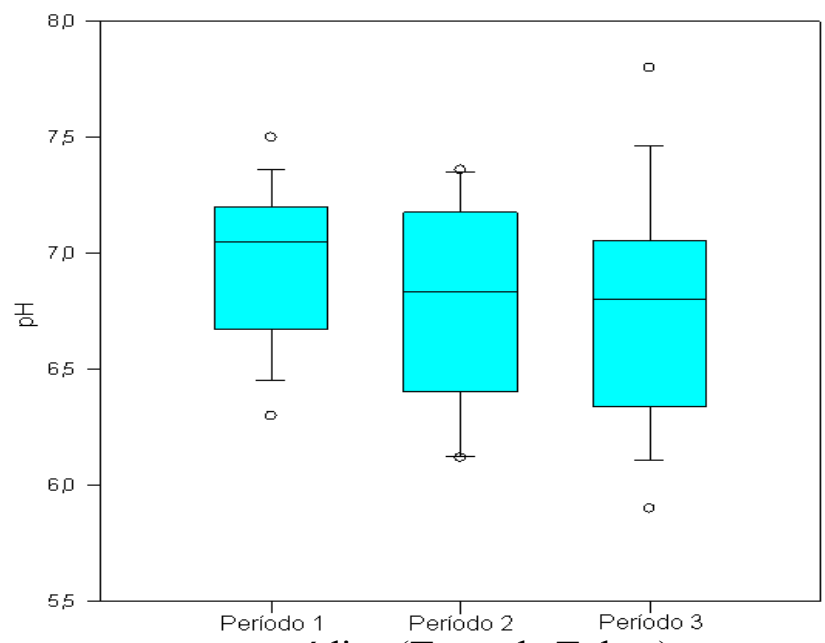

Figura 5. Box plot e comparação entre médias (Teste de Tukey) mostrando a variação do $\mathrm{pH}$ com diferenças significantes no córrego do Cintra em 1999, 2008 e 2009.

Para o parâmetro $\mathrm{CE}$, a Tabela 2 mostra que o $\mathrm{P}_{1}$, no primeiro período, difere estatisticamente em relação aos outros períodos. A quantidade elevada de sais dissolvidos na água é provocada pela mineralização da matéria orgânica (Nuvolari et al. (2003) e, mesmo com o encaminhamento de esgoto neste ponto ao sistema ETE-SABESP a partir de 1999, foi observada elevada concentração de sais que influenciou na qualidade da água nas análises realizadas em 2008 e 2009 (Tabela 2). Possivelmente ainda existia lançamento de esgoto indevido neste ponto, cujo média anual de CE aproximou-se a $100 \mu \mathrm{S}_{\mathrm{cm}} \mathrm{cm}^{-1}$, valor esse indicativo de ambiente impactado (CETESB, 2010).

Tabela 2. Resultados do teste de Tukey para o CE $\left(\mu \mathrm{S} . \mathrm{cm}^{-1}\right)$ nos quatro pontos de coleta no córrego do Cintra, nos períodos de 1999, 2008 e 2009.

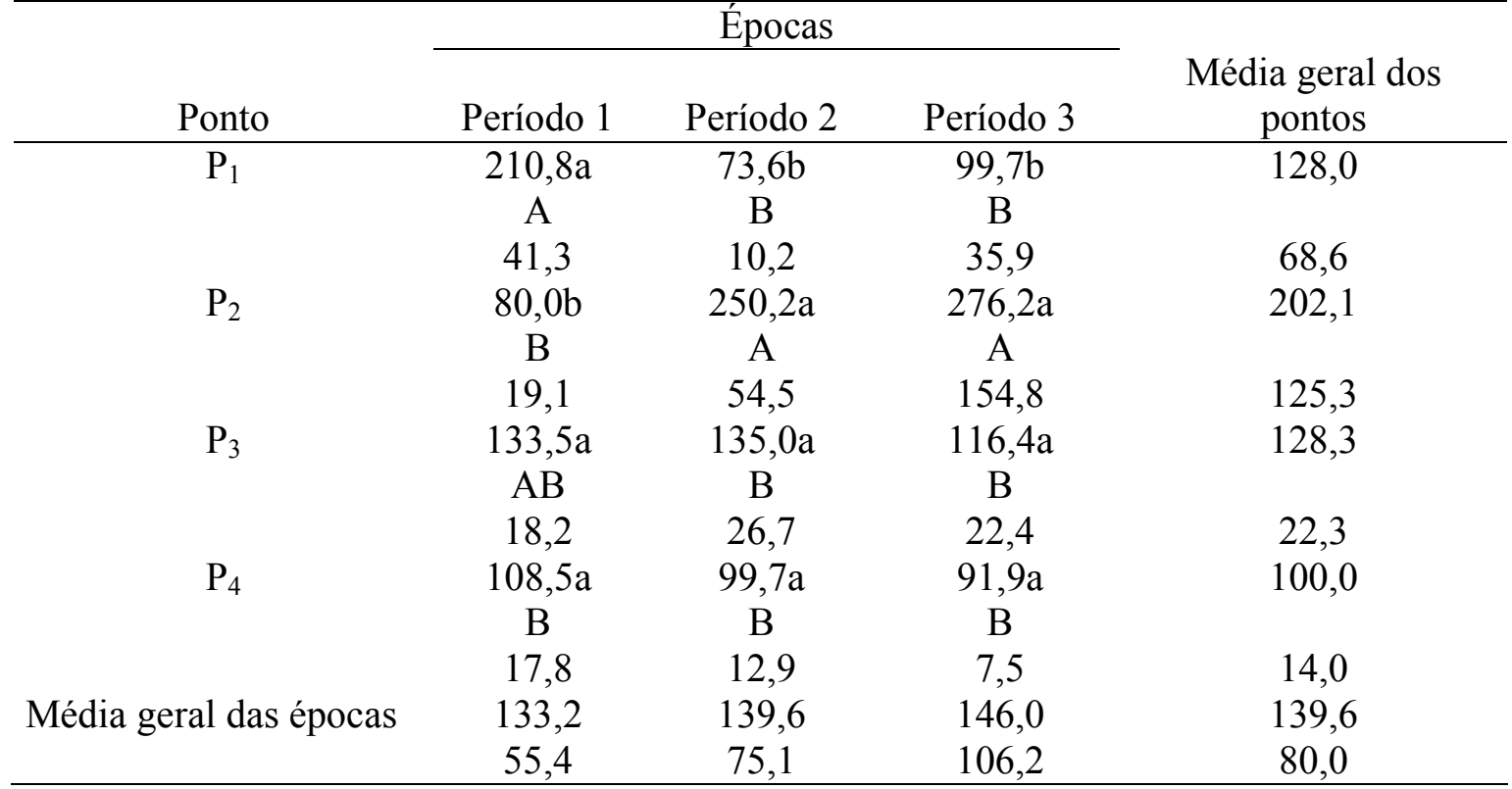


$\mathrm{P}<0,001$ para efeito da interação época* ponto

Letras minúsculas comparam médias de época dentro de cada ponto

Letras maiúsculas comparam médias de ponto dentro de cada época

$\mathrm{O} \mathrm{P}_{2}$ no, $1^{\circ}$ período (Tabela 1 ), localizado a jusante do sistema ETE-SABESP, demonstra melhora da qualidade do efluente tratado, o que difere dos $2^{\circ}$ e $3^{\circ}$ períodos que se elevaram consideravelmente os valores ultrapassando os limites desejáveis. A Figura 6, mostra elevada carga de sais dissolvidos no $\mathrm{P}_{2}$ nos 3 períodos em relação aos demais pontos.

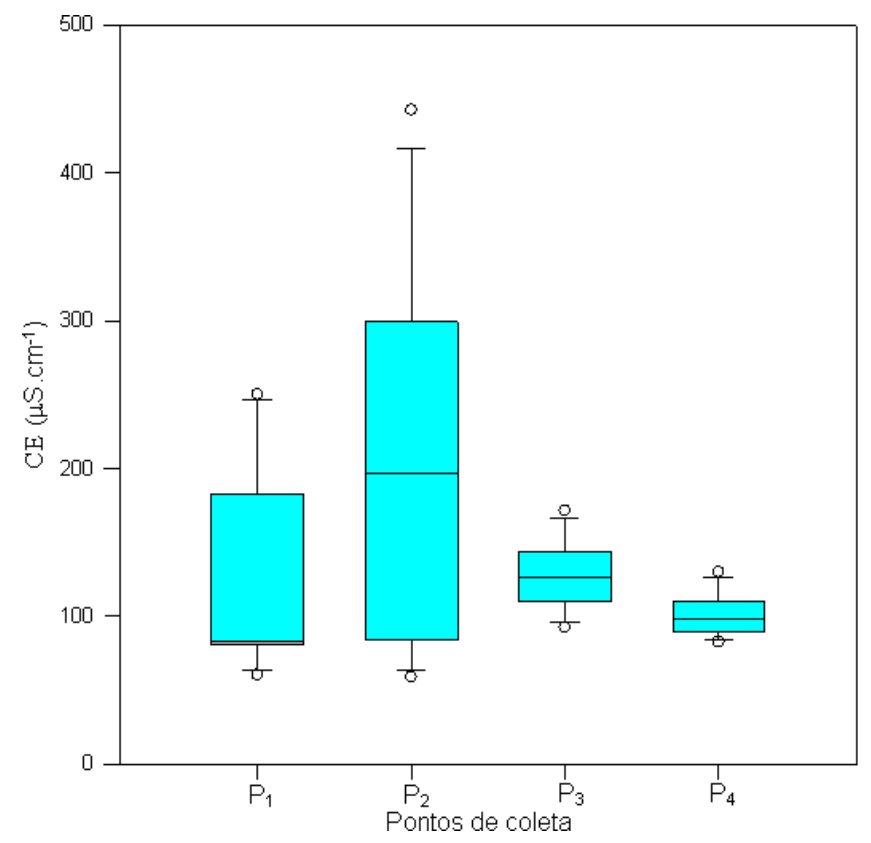

Figura 6. Box plot e comparação entre médias (Teste de Tukey) mostrando a variação do CE $\left(\mu \mathrm{S} . \mathrm{cm}^{-1}\right)$ com diferenças significantes no córrego do Cinta nos quatro pontos de coleta em 1999, 2008 e 2009.

Entre 1999 e 2009 possivelmente ocorreu o aumento da carga de esgoto a ser tratado $\left(\mathrm{P}_{2}\right)$ o que justifica o aumento da CE. Quanto à qualidade de efluente neste ponto, Souza (2005), estudou durante um ano (2004) o efluente da $3^{\text {a }}$ lagoa de estabilização e verificou que sua qualidade estava dentro dos limites permissíveis pela legislação vigente. Nos pontos 3 e 4 durante os 3 períodos não houve variação estatística e se observa que os valores diminuem gradativamente à medida que se afastam dos pontos 1 e 2 (Figura 6). Este fenômeno ocorre devido ao efeito de diluição das águas do córrego também observado por Gralhóz \& Nogueira (2006), Belluta et al (2009) e Belluta et al (2010ab).

$\mathrm{Na}$ Figura 7, o Box plot mostra o comportamento dos resultados da CE em cada período separadamente considerando os 4 pontos juntos. Nos 3 períodos observa-se que a amplitude dos valores apresenta tendência a outlier. Isto pode ter ocorrido devido a aumentos pontuais de carga de efluente gerada nos últimos anos e aos períodos de estiagem em que foram realizadas as coletas onde os valores excederam em relação à mediana. Nos estudos de Belluta et al (2010a), 
foi observado que em períodos diferentes, no inverno (baixa pluviosidade), a CE se elevou consideravelmente e no verão ocorreu o inverso, devido ao efeito de diluição dos sais dissolvidos provocado pelas águas das chuvas. Os mesmos resultados foram obtidos por Psilovikos et al. (2006), onde verificaram que os baixos valores da CE coincidem com os elevados níveis de água do rio Nestos (Bulgária), devido ao efeito de diluição.

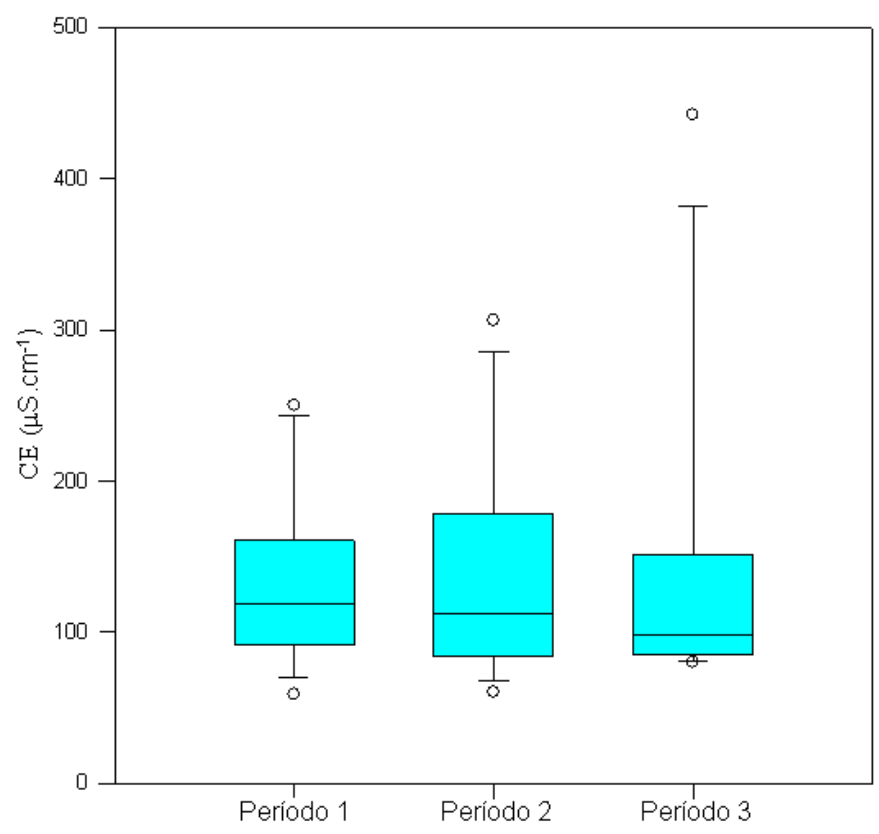

Figura 7. Box plot e comparação entre médias (Teste de Tukey) mostrando a variação do pH com diferenças significantes no córrego do Cintra em 1999, 2008 e 2009.

Na Tabela 3, o $\mathrm{P}_{1}$ apresenta valores de OD somente no Período 1, visto que nos outros períodos a concentração foi de $0,00 \mathrm{mgO} . \mathrm{L}^{-1}$, observado também na Figura 8. Isto ocorreu devido à presença de lançamento de esgoto diretamente no córrego nos períodos 2 e 3 provocando a depleção de OD na água pela decomposição biológica da matéria orgânica (Grenberg et al, 2005).

Tanto os parâmetros de $\mathrm{pH}$ e CE revelavam indícios de possível lançamento de esgoto nestes pontos devido a acidez, presença de sais dissolvidos e a constatação de odores no local da coleta. Como não há OD na água neste trecho do córrego, através de várias diluições da amostra no laboratório (Grenberg et al, 2005), foi possível determinar a concentração da $\mathrm{DBO}_{5}($ Tabela 4).

Nos pontos 2, 3 e 4, os valores de OD não variaram estatisticamente entre si nos períodos 2 e 3 conforme as letras minúsculas, mas variaram em relação ao Período 1 (Tabela 3). Apesar dos valores obtidos em todos os pontos e períodos, considerando que o $\mathrm{P}_{2}$ é efluente tratado do sistema ETE - SABESP, o OD manteve-se com valores superiores a $5 \mathrm{mgO}$. $\mathrm{L}^{-1}$, pois são níveis satisfatórios para preservação da biota aquática. (Brasil, 2005). 
Tabela 3. Resultados do teste de Tukey para o OD $\left(\mathrm{mg} \mathrm{O} \cdot \mathrm{L}^{-1}\right)$ nos quatro pontos de coleta no córrego do Cintra, nos períodos de 1999, 2008 e 2009.

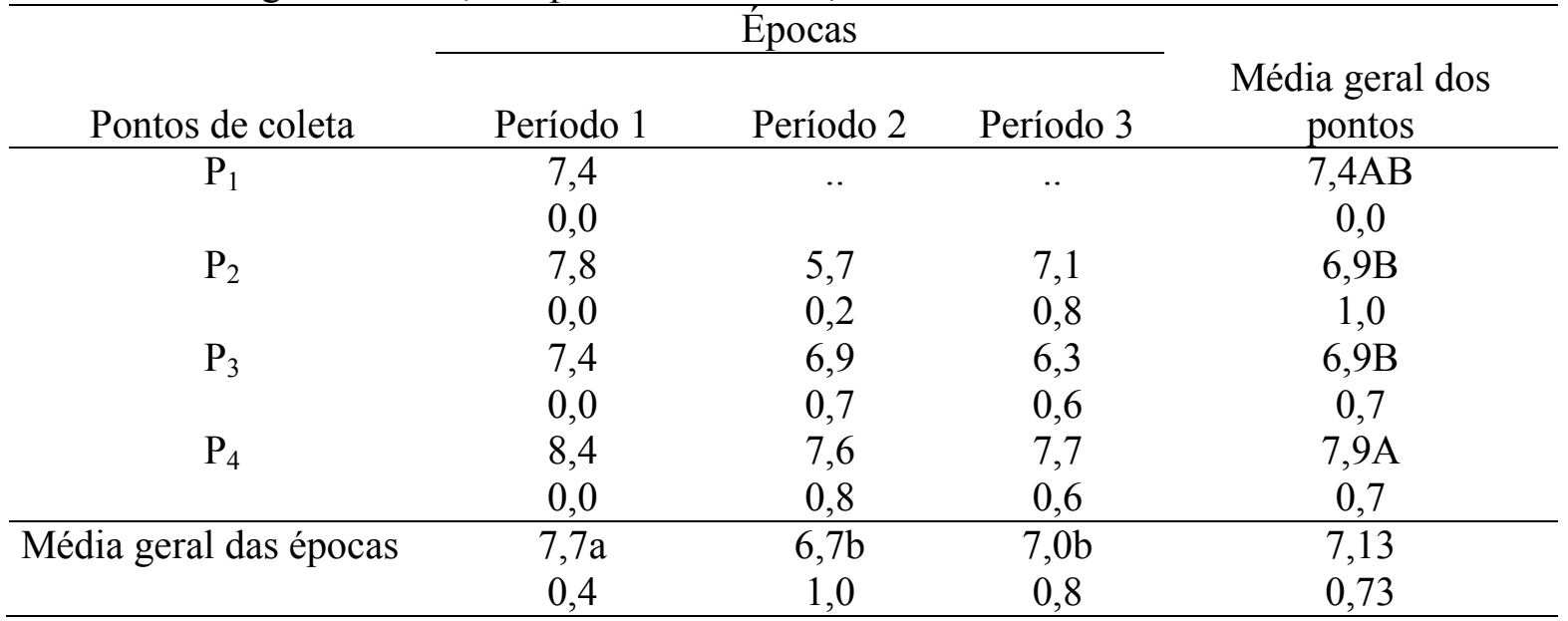

$\mathrm{P}=0,005$ para ponto e $\mathrm{p}=0,003$ para época

Letras minúsculas comparam médias de época

Letras maiúsculas comparam médias de pontos

A Figura 8 mostra assimetria dos resultados para o parâmetro OD entre os pontos 2,3 e 4 nos 3 períodos. Da mesma forma que ocorreu com a CE (Figura 6), o $\mathrm{P}_{2}$ apresentou elevada amplitude dos valores do OD, cuja dispersão possivelmente ocorreu devido à variação do teor de carga orgânica proveniente do sistema ETE - SABESP obtida em cada momento da coleta. Na mesma figura, o $\mathrm{P}_{3}$ e $\mathrm{P}_{4}$ apresentaram menor dispersão e amplitude dos valores. Nota-se que a concentração do OD é crescente à medida que atinge a foz da microbacia devido a autodepuração provocada pela turbulência e aumento do volume das águas pelos rios tributários também observado por Gralhóz \& Nogueira (2006), Belluta et al (2009) e Belluta et al (2010ab). Nos estudos de Massoud et al. (2006), o rio Abo Ali, no Líbano, foi seriamente comprometido pelo lançamento de esgoto, mas a jusante deste local, houve melhora dos níveis de OD no seu percurso com o aumento do índice de chuvas, contribuição dos rios tributários e a turbulência das águas. Segundo estudos de Belluta et al. (2009) realizado na mesma área do presente estudo, ao contrário de tantas nascentes, o Córrego do Cintra está seriamente comprometido logo na cabeceira com depleção de OD, mas o nível se eleva gradativamente até a foz. 


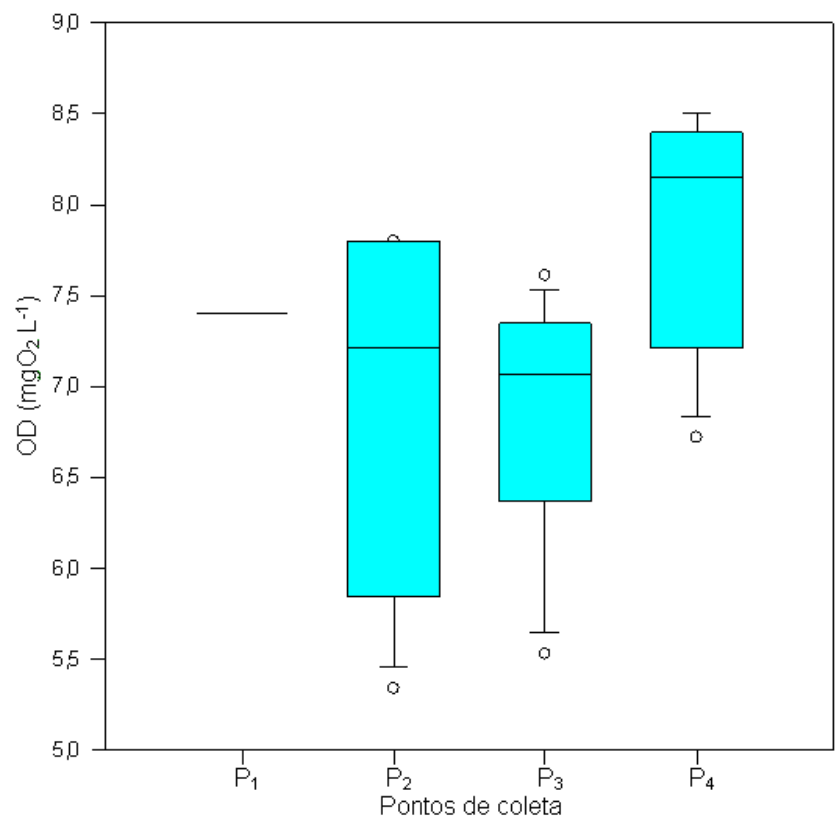

Figura 8. Box plot e comparação entre médias (Teste de Tukey) mostrando a variação do OD $\left(\mathrm{mg}\right.$ O.L $\left.\mathrm{L}^{-1}\right)$ com diferenças significantes no córrego do Cinta nos quatro pontos de coleta em 1999, 2008 e 2009.

Em se analisando por períodos, observa-se que na Figura 9 ocorre menor amplitude dos resultados e melhores valores de qualidade da água no $1^{\circ}$ período. Nos períodos 2 e 3 houve maior dispersão dos valores cuja amplitude variou significativamente. As coletas realizadas na escala temporal demonstraram variável consumo de OD em função de descargas lançadas no córrego durante as coletas. No entanto, para a Classe II do CONAMA (Brasil, 2005), os teores encontrados no presente trabalho são aceitáveis para OD, pois são superiores a $5 \mathrm{mg} \mathrm{O} . \mathrm{L}^{-1}$, mas os corpos d'água que recebem efluente tratado deve ser monitorado juntamente com outros parâmetros de qualidade de água. 


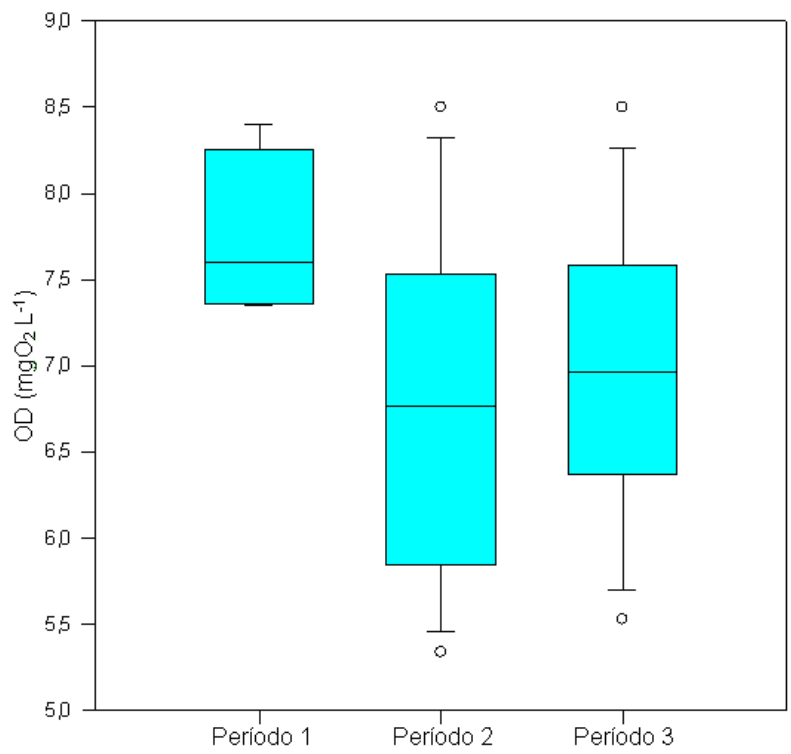

Figura 9. Box plot e comparação entre médias (Teste de Tukey) mostrando a variação do pH com diferenças significantes no córrego do Cintra em 1999, 2008 e 2009.

$\mathrm{Na}$ Tabela 4, os valores de $\mathrm{DBO}_{5}$ variaram estatisticamente como mostram as letras maiúsculas da média entre os pontos. Observa-se que a maior demanda de oxigênio ocorreu no $\mathrm{P}_{1}$ em todos os períodos, podendo ser observado também na Figura 10, o que revela presença de matéria orgânica no corpo d'água.

Tabela 4. Resultados do teste de Tukey para o DBO (mg O.L $\left.\mathrm{L}^{-1}\right)$ nos quatro pontos de coleta no córrego do Cintra, nos períodos de 1999, 2008 e 2009.

\begin{tabular}{|c|c|c|c|c|}
\hline \multirow[b]{2}{*}{ Ponto } & \multicolumn{3}{|c|}{ Épocas } & \multirow[b]{2}{*}{ Média geral dos pontos } \\
\hline & Período 1 & Período 2 & Período 3 & \\
\hline \multirow[t]{2}{*}{$\mathrm{P}_{1}$} & 6,7 & 7,2 & 6,9 & $6,9 \mathrm{~A}$ \\
\hline & 0,0 & 1,7 & 2,0 & 1,4 \\
\hline \multirow[t]{2}{*}{$\mathrm{P}_{2}$} & 3,8 & 5,4 & 6,9 & $5,4 \mathrm{~B}$ \\
\hline & 0,0 & 0,3 & 0,9 & 1,4 \\
\hline \multirow[t]{2}{*}{$\mathrm{P}_{3}$} & 3,6 & 4,1 & 3,3 & $3,7 \mathrm{D}$ \\
\hline & 0,0 & 1,8 & 2,2 & 1,5 \\
\hline \multirow[t]{2}{*}{$\mathrm{P}_{4}$} & 4,4 &.. & .. & $4,4 \mathrm{CD}$ \\
\hline & 0,0 & & & 0,0 \\
\hline $\begin{array}{l}\text { Média geral das } \\
\text { épocas }\end{array}$ & 4,6 & 5,6 & 5,7 & 5,2 \\
\hline & 1,3 & 1,8 & 2,4 & 1,9 \\
\hline
\end{tabular}

$\mathrm{P}<0,001$ para ponto e $\mathrm{p}=0,23$ para época

Letras maiúsculas comparam médias de pontos

Analisando os pontos 2 e 3 em 2008 e 2009 (Tabela 1), apresentaram-se mais elevados em relação ao Período 1. Isto permite dizer que nestes pontos, piorou a condição da qualidade da água nos últimos anos. Os parâmetros estudados no presente trabalho foram estudados por 
Belluta et al (2009) e Belluta et al (2010ab) e demonstrou que a autodepuração da água do córrego do Cintra ocorre devido à redução gradativa da demanda de oxigênio. Além disso, os pontos 3 e 4 sofrem o efeito residual da carga orgânica geradas nas nascentes do córrego e a diluição provocada pelos rios tributários pode ser verificado pelo decréscimo da $\mathrm{DBO}_{5}$ (Figura 10). $\mathrm{A} \mathrm{DBO}_{5}$ no $\mathrm{P}_{4}$ nos períodos 2 e 3 não foi analisado devido a melhor qualidade da água e, conseqüentemente, menor demanda de oxigênio.

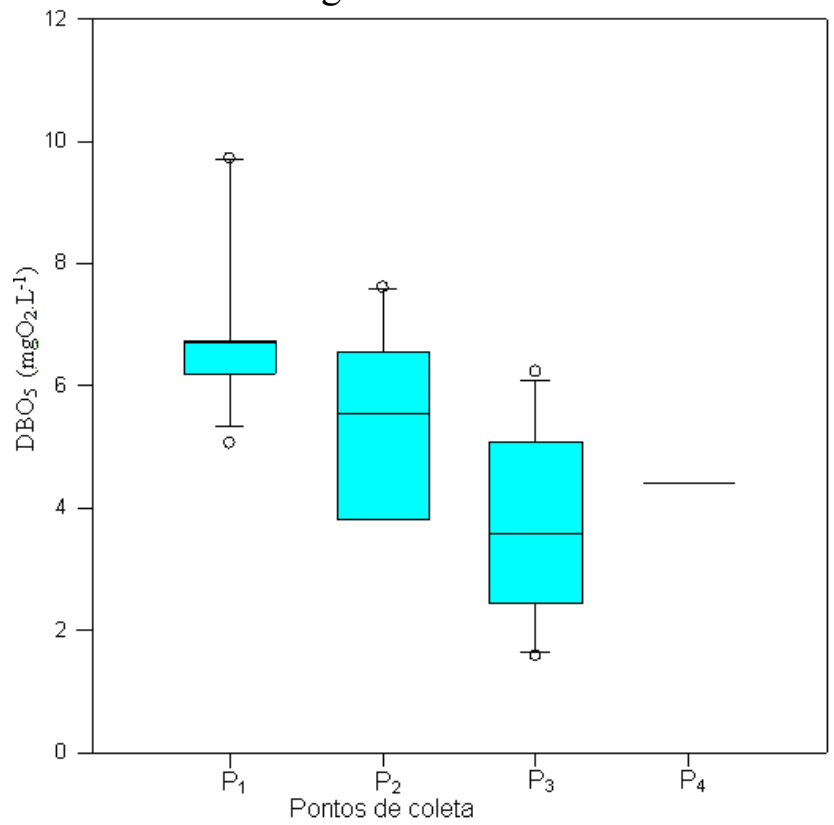

Figura 10. Box plot e comparação entre médias (Teste de Tukey) mostrando a variação do DBO (mg O.L $\left.\mathrm{L}^{-1}\right)$ com diferenças significantes no córrego do Cinta nos quatro pontos de coleta em 1999, 2008 e 2009.

A Figura 11 revela o comportamento da $\mathrm{DBO}_{5}$ em cada período e em todos os pontos. No Período 1, os valores estavam próximos da mediana, pois não houve grande dispersão dos resultados. A elevada carga orgânica gerada no sistema ETE-SABESP nos pontos 1 e 2, influenciaram significativamente na qualidade da água no curso do rio da presente sub-bacia. Os períodos 2 e 3 na Figura 11, mostra grande dispersão dos valores em função das coletas nas estações do ano visto que a demanda de oxigênio está em função da crescente carga de esgoto gerado nos pontos 1 e 2 e os períodos de menor pluviosidade durante $\mathrm{o}$ ano. 


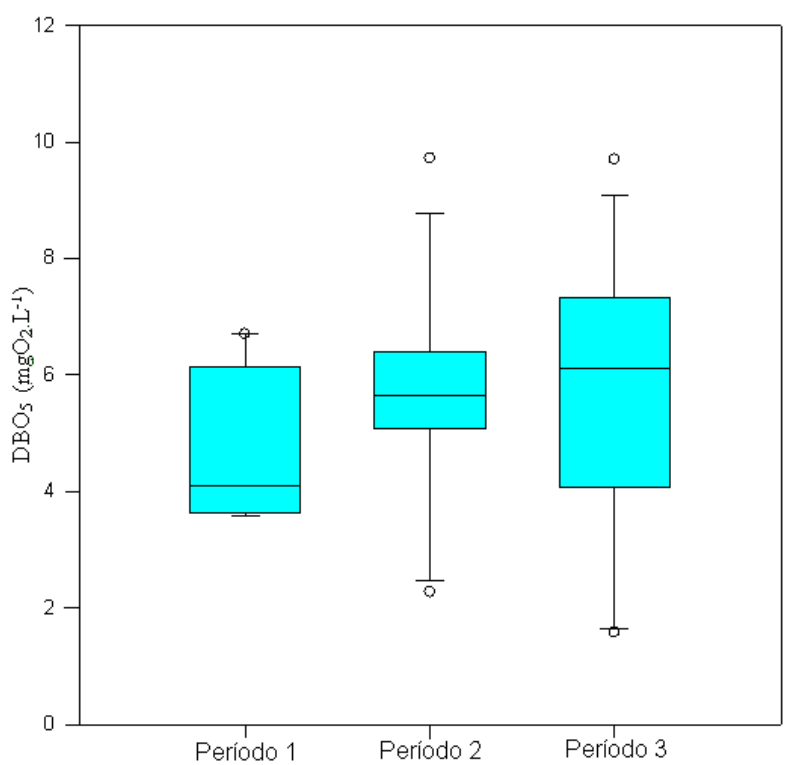

Figura 11. Box plot e comparação entre médias (Teste de Tukey) mostrando a variação do DBO (mg O.L $\mathrm{L}^{-1}$ )com diferenças significantes no córrego do Cinta nos quatro pontos de coleta em 1999, 2008 e 2009

O uso de imagens de satélite e Sistema de Informação Geográfica para avaliar fitofisionomias de uma sub-bacia hidrográfica, foi rápido e facilitou muito o trabalho de pesquisa principalmente tratando-se de análise temporal. A análise das classes de ocupação do solo no presente estudo nos 2 períodos, nos dá a dimensão da interação espacial e temporal entre o homem e o meio ambiente. Aliado a estas alterações, o controle de qualidade de água de um córrego, nos alerta quanto às contaminações pontuais e difusas no seu percurso.

Neste contexto, a sub-bacia do córrego do Cintra contribui para o reservatório do Tietê (Bacia do Tietê) e está diretamente relacionada ao processo de transporte e deposição de sedimentos e poluentes no mesmo corpo d'água, pois vai determinar a intensidade dos processos erosivos, da permeabilidade da sub-bacia, da aplicação de defensivos agrícolas, da redução da vegetação natural, da conservação do solo e das margens dos rios.

Políticas públicas que incentivem o gerenciamento dos recursos hídricos em nível de bacias hidrográficas de forma integrada e participativa (CATI, 2010), como forma de reduzir as fontes pontuais e difusas de poluição, asseguram melhor qualidade aos recursos hídricos e na qualidade de vida das comunidades de maneira sustentável. De acordo com Ferreira Júnior et al. (2009), a legislação brasileira prevê a proteção dos serviços ambientais para a proteção da biodiversidade. Serviços como a proteção dos solos contra erosão e regulação e manutenção do ciclo hidrológico podem possibilitar, além da recarga satisfatória dos mananciais, a proteção das margens dos cursos d'água, impedindo o assoreamento.

Dada a complexidade do estudo da bacia hidrográfica na utilização de imagens, no tempo gasto para a avaliação e diagnóstico das áreas, além das análises da qualidade da água do córrego do Cintra, não foi suficiente para uma completa análise de toda a dinâmica envolvida na bacia tais como aspectos hidrológicos da mata ciliar e a diversidade de espécies nativas encontradas 
para utilização em plantios. Portanto, este estudo constitui-se em um apoio para pesquisas futuras.

\section{CONCLUSÃO}

Através de técnicas de geoprocessamento na sub-bacia do córrego do Cintra entre 1984 e 2010, foi observado que grande parte da pastagem (25,5\%) foi substituída pelas demais classes, possivelmente pelo baixo investimento na criação de gado. Dentre essas classes, a mais importante foi a regeneração da mata nativa e reflorestamento que aumentou significativamente $(5,08 \%)$. As áreas brejosas e desprovidas de mata ciliar no entorno do $\mathrm{P}_{3}$ e $\mathrm{P}_{4}$, necessitam de técnicas de restauração e manejo de sucessão ecológica nas áreas degradadas como o resgate de plântulas e a semeadura direta com diversidade de espécies locais para a recomposição da sua mata original;

Foi identificada contaminação pontual $\left(\mathrm{P}_{1}\right.$ e $\left.\mathrm{P}_{2}\right)$ e piora na qualidade de água do córrego do Cintra nos demais pontos nos períodos de 2008 e 2009. Reintegração do esgoto indevido $\left(\mathrm{P}_{1}\right)$ no sistema tronco (ETE-SABESP), bem como o monitoramento e adequação do sistema à carga atual de esgoto a ser tratado, serão necessárias para melhorar a qualidade da água no percurso do córrego. A adoção de técnicas de manejo adequado do solo, respeitando as áreas de nascentes e de preservação permanente juntamente com educação ambiental junto à população ribeira também será importante para restabelecer a recomposição vegetal e com isso melhorar a qualidade da água do córrego do Cintra.

\section{REFERÊNCIAS}

ALENCAR, A. A. C.; VIEIRA, I. C. G.; NEPSTAD, D. C.; LEFEBVRE, P. Análise multitemporal do uso do solo e mudança da cobertura vegetal em antiga área agrícola da amazônia oriental. Anais VIII Simpósio Brasileiro de Sensoriamento Remoto, Salvador, Brasil, 14-19 abril 1996, INPE, p. 475-478.

BELlUTA, I; SILVA, A.M.M.; CAMARGO, C.H.C.; RALL, V.L.M. Impacts on the springs of Cintra Stream (Botucatu, São Paulo State, Brasil) and downstream variations in water quality. Acta Limnol. Bras., Porto Alegre RS, 2009, v. 21, p.11-24.

Belluta, I, AlaOR, A. A., COElho, J. C., NASCimento, A. B., Silva, A. M. M. Avaliação temporal e espacial no córrego do Cintra (Botucatu-SP) frente aos defensivos agrícolas e parâmetros físico-químicos de qualidade da água - Um estudo de caso. Revista Energia, Botucatu SP, 2010a, v. 25, nº 2, p. 54 -73.

BELLUTA, I, SILVA, A. M. M., VALENTE, J. P. S. The importance of watershed studies: the Cintra Stream Micro-watershed Model. Revista Multiciencias, Falcón- Venezuela, 2010b, v. 10, n. 3 , p. 225-233.

BRASIL. Lei $\mathrm{n}^{\circ}$ 4.771, de 15 de setembro de 1965. Institui o novo Código Florestal Disponível em: https://www.planalto.gov.br/ccivil_03/leis/L4771.htm. Acesso em: 20 de agos. 2008. 
BRASIL. Resolução CONAMA n. 357, de 17 março de 2005. Dispõe sobre a classificação dos corpos de água e diretrizes para seu enquadramento, bem como estabelece as condições e padrões de lançamento de afluentes e dá outras providências. Disponível em http://www.mma.gov.br/port/conama/. Acessado em 10/set/2008.

CHABARIBERY, D; SILVA, J. R.; TAVARES, L. F. J.; LOLI, M. V. B. ; SILVA, M. R.; MONTEIRO, A. V. V. M. Recuperação de matas ciliares: sistemas de formação de floresta nativa em propriedades familiares. Informações Econômicas, SP, v.38, n.6, 2008.

CANDESSUS, M.; BADRÉ, B.; CHÉRET, I.; TÉNIÈRE-BUCHOT, P. F. Água: Oito milhões de mortos por ano. Um escândalo mundial. Rio de Janeiro, $2^{\mathrm{a}}$ ed., 2010, 272 p.

COMPANHIA DE TECNOLOGIA E SANEAMENTO AMBIENTAL. Variáveis de qualidade de água. São Paulo, 2010.Disponível em: $<\underline{\text { http://www.cetesb.sp.gov.br/agua/rios/ }}$ variaveis.asp >. Acesso em: 03 de out. 2010.

COORDENADORIA DE ASSISTÊNCIA TÉCNICA INTEGRAL. Programa Estadual de Microbacias Hidrográficas. Portal do Governo do Estado de São Paulo.

<www.cati.sp.gov.br/cati/-projetos/pemh/pemg.php>. Acesso em: 01 nov. 2010.

DURIGAN, G. Estrutura e diversidade de comunidades florestais. In: Martins, S. V. Ecologia de florestas tropicais do Brasil. 1 ${ }^{a}$ ed.Minas Gerais:Viçosa, 2009. cap. 6, p. 185-210.

EASTMAN, J.R. Idrisi 15: The Andes Edition.Worcester, MA: Clark University, 2006.

ENGEL, V.E.; PARROTA, J.A. 2003. Definindo a restauração ecológica : tendências e perspectivas. In : KAGEYAMA, P.Y.; OLIVEIRA, R. E.; MORAES, L.F.D.; ENGEL, V.L.; GANDARA, F.B. Restauração Ecológica de Ecossistemas Naturais. Botucatu: FEPAF, cap 1: 3 26.

FERREIRA JÚNIOR, W. G.; SCHAEFER, C. E. G. R.; SILVA, A. F. Uma visão pedogeomorfológica sobre as formações florestais da Mata Atlântica. In: Martins, S. V. Ecologia de florestas tropicais do Brasil. $1^{\text {a }}$ ed. Minas Gerais: Viçosa, 2009. cap. 4, p. 109 a 142.

GRALHÓZ, G.; NOGUEIRA, M. G. Eutrofização e contaminação crônica de um riacho de Cuesta (Córrego do Cintra) e avaliação do sistema de tratamento de esgotos. São Carlos: Instituto Internacional de Ecologia e Gerenciamento Ambiental; Academia Brasileira de Ciências; Conselho Nacional de Desenvolvimento Científico e Tecnológico, 2006. p. 119-140.

GREENBERG, A. E.; RICE, E. W.;CLESCERI, L. S.; EATON, A D. (2005). Standard methods for examination of water and wastewater., 21. ed. Washington: American Water Works Association and Water Pollution Control Federation. 1368 p.

INSTITUTO BRASILEIRO DE GEOGRAFIA E ESTATÍSTICA. Manual técnico da vegetação brasileira. Rio de Janeiro. Institudo Brasileiro de Geografia e Estatística. 1992. 92 p. 
INSTITUTO BRASILEIRO DE GEOGRAFIA E ESTATÍSTICA Contagem da população. Disponível em http://www.ibge.gov.br/home/estatística/população/contagem2007/default.shtm>. Acessado em 21/ago/2008

LIMA, W.P. Princípios de hidrologia florestal para manejo de bacias hidrográficas. Piracicaba: Escola Superior de Agricultura "Luiz de Queiros", USP. 1996. 318 p

LIMA, P. R. A. Balanço de espécies químicas em microbacias sob utilização agrícola: região de Botucatu SP. 2003. 122 f. Tese (Doutorado Agronomia: Energia na Agricultura)-Faculdade de Ciências Agronômicas, Universidade Estadual Paulista, Botucatu, 2003.

MARTINS, S.V.; RIBEIRO, G.M.; SILVA JUNIOR, W.M.; NAPPO, M.E. Regeneração pós fogo em um fragmento de floresta estacional semidecidual no município de Viçosa, MG. Ciência Florestal, 2002, v.2: 11-19.

MARTINS, S.; V.RODRIGUES, R. R.; GANDOLFI, S.; CALEGARI, L. Sucessão ecológica: Fundamentos e aplicações na restauração de ecossistemas florestais. Ecologia de florestas tropicais do Brasil. UFV, In: Martins, S. V. Ecologia de florestas tropicais do Brasil. $1^{\text {a }}$ ed. Minas Gerais:Viçosa, 2009. cap. 1, p. 19 a 39.

MASSOUD, M. A.; EL-FADEL, M.; SCRIMSHAW, M. D.; LESTER, J. N. Factors influencing development of managemment strategies for the Abou Ali River in Lebanon II: Seasonal and annual variation. Science of the total Environment. V. 362, 2006, 31-41.

NUVOLARI, A. et al.. As diversas opções de tratamento do esgoto sanitário. São Paulo: Edgard Blücher, 2003. 520 p.

PAULA LIMA, W e ZÁKIA, M. J. B. Hidrologia de matas ciliares. In: RODRIGUES, R. R. e LEITÃO FILHO, H. Matas ciliares. Conservação e recuperação. São Paulo. Editora da Universidade São Paulo. 2000. p. 33-44.

PSILOVIKOS, A.; MARGONI, S.; PSILOVIKOS, A. Simulation and trend analysis of the water quality monitoring daily data in Nestos river delta: contribution to the sustainable management and results for the years 2000-2002. Environmental Monitoring and Assessment, Netherlands, v. 116, p. 543-562, 2006.

SANTOS, A. F. Morfometria da microbacia hidrográfica do Ribeirão Faxinal, Botucatu SP e alterações em suas áreas de biomassa no período de 1972 a 2000 . Botucatu: UNESP, Faculdade de Ciências Agronômicas, 2004. 59 f.

SCHAEFER, C. E. G. R.; MENDONÇA, B. A. F.; FERREIRA JÚNIOR, W. G.; VALENTE, E. L.; CORREAA, G. R. Relações solo-vegetação em alguns ambientes brasileiros: Fatores edáficos e florística. In: In: Martins, S. V. Ecologia de florestas tropicais do Brasil. $1^{a}$ ed. Minas Gerais:Viçosa, 2009. cap. 5, p.142-184. 
SILVA, A. M. M., HENRY, R., CARVALHO, L. R., SANTINI, J. A. J. A capacidade de autodepuração de um curso d'água: Um estudo de Caso no Rio Pardo (Botucatu, SP). Acta Limnológica Brasiliensia. Porto Alegre RS, v. 10, n. 2, 1998, 83-99.

SOKAL, R.R. e ROHLF, F.J. (1995). Biometry: The principles and practice of statistics in biological research, 3a. ed., W.H. Freeman, New York, 887p.

SOUZA, A. J. et al. Aspectos físicos do município de Botucatu - SP. Revista Ciência Geográfica, Bauru, v. 9, n. 1, p. 54-75, 2003.

SOUZA, K. F. Caracterização da qualidade de efluentes e a possível utilização da biomassa como fonte energético. 2005. $221 \mathrm{f}$. Dissertação (Mestrado em Agronomia)-Faculdade de Ciências Agronômicas, Universidade Estadual Paulista, Botucatu, 2005.

TOLEDO, L. G. e NICOLELLA, G. Índice de qualidade de água em microbacia sob uso agrícola e urbano. Scientia Agricola, v.59, n.1, p.181-186, 2002.

TUNDISI. Água no século XXI: Entendendo a escassez. 2a ed. São Carlos, Ed. Rima, 2005. $251 \mathrm{p}$.

WATER ENVIRONMENT FEDERATION (WEF). Odor Control in Wastewater treatment Plants: Manual of practice $\mathbf{n}^{\mathbf{0}} 2$. New York: ASCE Manuals and Reports on Engineering Practice $n^{\circ}$ 82, 1995. 282p. 